\title{
HOPE IN PEOPLE WITH APHASIA
}

F.A.S Bright ${ }^{1}$, N.M Kayes ${ }^{1}$, C.M. McCann ${ }^{2}$ and K.M. McPherson ${ }^{1}$

${ }^{1}$ Person Centred Research Centre, Health and Rehabilitation Research Institute, AUT University. Private Bag 92006, Auckland 1142, New Zealand.

2Department of Psychology Speech Science. The University of Auckland Private Bag 92019, Auckland 1142, New Zealand

Short title: $\quad$ Hope in people with aphasia

Corresponding Author:

Felicity Bright

Phone: +64 $99219999 \times 7097$

Fax: +6499219620

Email: felicity.bright@aut.ac.nz 


\begin{abstract}
Background: Hope is considered to be important for health, recovery and rehabilitation outcomes in a range of healthcare populations. Little is known about hope in people following stroke, and even less is known about hope in people with aphasia following stroke as they are commonly excluded from research in this field.
\end{abstract}

Aims: This study aimed to explore how hope was experienced by people with aphasia following stroke during the post-acute period of rehabilitation, and to identify factors influencing the experience of hope.

Methods and Procedures: This study utilised an Interpretive Description methodology. Data were collected through semi-structured interviews with five people with aphasia. Supported conversation techniques were used to facilitate full contribution of participants. Data were analysed using a number of approaches - coding, thematic analysis, narrative construction, diagramming and memoing.

Outcomes and Results: Hope was experienced in two ways. Simply 'having' hope was a broad but passive sense of hope which appeared to be the primary, constant form of hope. Actively hoping was an active, future-oriented form of hope that was experienced intermittently by participants. The experience of hope appeared dynamic and complex and seemingly influenced by three primary factors: uncertainty about the future; viewing hope as double-sided; and a sense of disruption. These were in turn influenced by a person's past experiences, present reality and perceived future.

Conclusions: Hope is considered important by people with aphasia. It appears related to how people engage in rehabilitation and may be influenced by clinicians. As such, it is a 
concept that therapists should be aware of. Suggestions for how clinicians may consider and address hope are provided and discussed. 


\section{INTRODUCTION}

Hope is said to be important in rehabilitation and living with illness or injury (Barker \& Brauer, 2005; Bluvol, 2003; Dorsett, 2010; Gum, Snyder, \& Duncan, 2006; Lohne \& Severinsson, 2004; Nekolaichuk, Jevne, \& Maguire, 1999; Simpson, 2004; Soundy, et al., 2010). It is commonly considered a multi-dimensional construct (Dufault \& Martocchio, 1985; Farran \& Popovich, 1990; Morse \& Doberneck, 1995; Nekolaichuk, et al., 1999) which may function as a way of being, relating, acting and/or thinking, in addition to being goaloriented (Bright, Kayes, McCann, \& McPherson, 2011).

A systematic review of hope in people with stroke identified three ways in which it has been conceptualised in the literature: as a broad sense; an outcome-oriented thought process; and an active process (Bright, et al., 2011). As a broad sense, hope was considered a state of being, positive and essential for life (Arnaert, Filteau, \& Sourial, 2006; Barker \& Brauer, 2005; Bays, 2001; Cross \& Schneider, 2010; Haggstrom, Axelsson, \& Norberg, 1994; Jones, Mandy, \& Partridge, 2008). This form of hope was often constant and unaffected by the stroke (Bays, 2001). Outcome-oriented hope bore similarities to goals, for example, hoping to return home or to return to normal (Bays, 2001; Jones, et al., 2008; Pilkington, 1999) but may not be an essential part of hope (Cross \& Schneider, 2010). As an active process, it incorporated cognitive engagement with hope alongside a process of acting on hopes. This could include evaluating hopes (Dowswell, Dowswell, Lawler, Green, \& Young, 2002) and participating in rehabilitation (Arnaert, et al., 2006; Barker \& Brauer, 2005; Bays, 2001). Levels of hope could fluctuate following stroke (Cross \& Schneider, 2010; Jones, et al., 2008) and could co-exist with emotions such as worry, uncertainty and fear (Arnaert, et al., 2006; Folden, 1994; Jones, et al., 2008). Hope could be developed and maintained 
through internal factors such as personal attitude, progress to date and stroke severity (Arnaert, et al., 2006; Barker \& Brauer, 2005; Bays, 2001; Cross \& Schneider, 2010;

Dowswell, et al., 2002; Jones, et al., 2008; Nilsson, Jansson, \& Norberg, 1997; Popovich, Fox, \& Bandagi, 2007; Pound, Bury, Gompertz, \& Ebrahim, 1994) and external factors such as social connections, spiritual sources and healthcare professionals (Arnaert, et al., 2006; Barker \& Brauer, 2005; Bays, 2001; Cross \& Schneider, 2010; Jones, et al., 2008; Popovich, et al., 2007; Pound, et al., 1994). Hope was generally considered a positive construct, a source of motivation (Arnaert, et al., 2006; Cross \& Schneider, 2010) that could help modulate mood, adjustment and ability to think about the future (Barker \& Brauer, 2005; Jones, et al., 2008; White, et al., 2008). Higher levels of hope were also associated with higher participation levels (Gum, et al., 2006) and quality of life (Bluvol, 2003; Cross \& Schneider, 2010; Tariah, Hersch, \& Ostwald, 2006).

One limitation of the literature discussed above was the inconsistent inclusion of people with aphasia (Bright, et al., 2011). It is not known if, or how, the presence of aphasia might impact on a person's experience of hope. Approximately one third of people may experience aphasia after a stroke (Kauhanen, et al., 2000; Pedersen, Jorgensen, Nakayama, Raaschou, \& Olson, 1995). As a result, excluding this group from research exploring hope after stroke means key information about the construct may be missing.

It has previously been reported that people with aphasia consider hope to be important, some seeing it as a source of motivation (Green \& Waks, 2008; Liechty \& Braun, 2006; Worrall, Davidson, Hersh, Howe, \& Sherratt, 2009). People with aphasia have suggested hope could be developed through relationships with others, being engaged in meaningful activities and accepting limitations (Green \& Waks, 2008; Liechty \& Braun, 
2006). A study in people with chronic aphasia found hope could be influenced by progress, "hopeful" language from healthcare providers and support networks (Hopper \& Edey, 2007). Tensions between hope and realism may exist, with patients seeking hope while professionals aim for realism (Hersh, Worrall, Howe, Sherratt, \& Davidson, 2012). Others have suggested removing hope could be devastating to the person with aphasia (Worrall, et al., 2009).

These studies highlight the importance of hope for those living with aphasia and that healthcare professionals need to be mindful of this, and the role they play in maintaining or diminishing hope. However, with the exception of Hopper and Edey (2007), none of these studies explicitly sought to explore hope. Rather it emerged as a theme in their findings. In addition, most studies were completed in the chronic period of recovery. While the definition of chronic aphasia varies (Luck \& Rose, 2007), it generally includes those beyond six or twelve months post stroke (e.g. Moss \& Nicholas, 2006; Barthel, Meinzer, et al., 2008; Cherney \& Halper, 2008). It is not known whether the views of people with chronic aphasia are the same as those with post-acute aphasia, who are in the early stages of adjustment to the stroke and its effects (Alaszewski, Alaszewski, \& Potter, 2004; Kirkevold, 2002) and whose communication abilities may be changing (Pedersen, et al., 1995). There is currently little known about hope in people during the post-acute period of rehabilitation despite this being the time when most therapy services are provided (Kirkland, 2008; Sarno, 2004). In addition, there is little known about the processes that underlie a person's experience of hope. Exploring the experience of hope in people with aphasia during the post-acute period may further our understanding of hope after stroke. 
The current study sought to answer the questions: (1) How do people with aphasia experience hope in the post-acute period of rehabilitation? and, (2) What factors appear to influence a person's experience of hope?

\section{METHODS}

This exploratory study of hope in people with aphasia drew on a qualitative methodology, Interpretive Description (Thorne, 2008; Thorne, Kirkham, \& MacDonald-Emes, 1997; Thorne, Kirkham, \& O'Flynn-Magee, 2004). This methodology was considered appropriate given the study's aim to support therapists to address hope in practice as findings of an Interpretive Description study should be easily incorporated into practice (Thorne, 2008). The approach also allows multiple approaches to data collection and analysis; this enabled the research process to be tailored to meet the communicative needs of the participants. Finally it is appropriate for exploratory research (Hunt, 2009; Thorne, 2008; Thorne, et al., 2004).

\section{PARTICIPANTS}

People were eligible for the study if they: had a left hemisphere stroke resulting in aphasia; were able to communicate with the researcher verbally or non-verbally with support; were currently receiving their first episode of outpatient or community based speech-language therapy in one of two rehabilitation services in a large metropolitan area in New Zealand; and, were aged 16-64 years. Purposeful sampling (Holloway \& Wheeler, 2002) was used to 
identify participants with the sampling criteria focusing on gender, ethnicity and severity of aphasia. Potential participants were given information about the study by their treating speech-language therapist. The contact details of those interested in participating were passed to the researcher with their consent.

Twelve people with aphasia were approached and seven expressed interest in participating in the study. Two were ineligible, one because their stroke was a right hemisphere stroke and the other was receiving their third episode of rehabilitation. In total, five people participated in the study. Details of the participants are presented in Table One. The participants' names are pseudonyms.

The Western Aphasia Battery - Revised (WAB-R) (Kertesz, 2006) was administered to ascertain the subtype and severity of aphasia. This was introduced four months after study commencement when it was identified that this information would help to describe participants. By the time additional ethics approval to administer the assessment had been sought and obtained it was up to nine months post-interview for the first three participants. It was completed as part of the interview process for the final two participants. The delay in completing it with three participants may have influenced the severity and type of aphasia indicated by the assessment as it is possible the aphasia had partially resolved by that time (Kauhanen, et al., 2000). However, informal observation suggested there was little change in these individual's communication patterns between the time of the interview and time of the assessment. Each participant's rehabilitation file was reviewed for demographic information and information about the stroke and its effects. 
---Insert Table One here ---

A number of techniques were used to gain informed consent (Kagan \& Kimelman, 1995). The written information sheet and consent form were designed using the principles of communication access (Brennan, Worrall, \& McKenna, 2005; Rose, Worrall, \& McKenna, 2003). The written material was supplemented with explanations of the study, using supported conversation techniques (Kagan, 1995) at multiple times throughout the recruitment and consent process. Written consent was gained prior to commencing data collection.

Ethical approval for the study was obtained through the Regional Health and Disability Ethics Committee and the University Ethics Committee.

\section{DATA COLLECTION}

Three semi-structured interviews were completed with each participant, over a three week period. These focused on definitions, perceptions, experiences and processes of hope in the time since their stroke. Questions included: "What does hope mean to you?", "Has hope changed since you had your stroke?", "What would happen if you didn't have hope?" and "What do you hope for?". Each interview was held in the participant's home and lasted 6090 minutes. Three interviews per participant were used to enhance their ability to contribute their perspectives and to ensure accurate interpretation of their data. The multiple interviews gave the researcher the opportunity to: identify communication strategies that would support individual participation; introduce concepts or questions in 
advance, giving participants time to consider their responses; and clarify responses from previous interviews and check preliminary findings.

The initial interview for each participant was audiorecorded and the second and third interviews were also videorecorded to allow for analysis of non-verbal communication (Luck \& Rose, 2007). Audiorecordings were transcribed. The videorecordings were viewed to capture non-verbal behaviour. In one instance the audio equipment failed so the interview was transcribed with as much detail as could be recalled. The transcription guide is attached in Appendix I.

\section{DATA ANALYSIS}

Analysis in Interpretive Description is inductive (Hunt, 2009; Thorne, et al., 2004) and can utilise multiple techniques (Hunt, 2009; Thorne, 2008; Thorne, et al., 2004). Data collection and analysis occurring simultaneously, each informed the other (Thorne, et al., 2004). This helped highlight gaps in knowledge, areas where clarification was needed and commonalities, patterns and differences in experiences and processes (Thorne, 2008; Thorne, et al., 2004). Coding was the dominant form of analysis and was supported with narrative construction, thematic analysis, diagramming and memoing. Coding was informed by grounded theory methods (Charmaz, 2006), specifically incident-by-incident, focused and axial coding. Constant comparison was used to compare codes and categories within and between participants. Thematic analysis and narrative construction were used to develop an intimate knowledge of each person's experience. Diagramming supported detailed exploration of the experience and process of hope, illustrating possible relationships between codes and gaps in analysis. Memos captured the researcher's thoughts about the 
emergent findings (Thorne, 2008). The analysis was verified through member-checking with participants, the second author reviewing and coding a subset of transcripts and regular meetings of the research team where the emergent findings were discussed and defended. Other strategies also contributed to rigour, including the use of multiple interviews, multiple analytic strategies and incorporating raw data into the text to support findings (Thorne, 2008). These data are incorporated within the text of the findings in a narrative, collective format where brief excerpts from a number of participants were relevant. This approach to reporting the findings was chosen because the presence of aphasia meant that the pertinent data were often in short quotes. A narrative format provides the context of the, at times, lengthy conversational act which included gesture, drawing and multiple attempts.

\section{FINDINGS}

Participants appeared to experience hope in two ways - simply 'having' hope and actively hoping. The interaction between these two forms of hope is demonstrated in Figure One. However, despite the apparent simplicity of hope as depicted in this figure, hope appeared dynamic, fluid and complex, influenced by a number of variables. Each form of hope is described, followed by a discussion of the factors that appeared to influence how hope was experienced. Data indicated that participants adopted a range of strategies to manage the tensions which appeared to be inherent in the experience of hope. 
--- Insert Figure One here ---

\section{SIMPLY 'HAVING' HOPE}

Simply 'having' hope was the primary form of hope experienced by all participants. It was a passive state where participants reported they felt the presence or a sense of hope. It was described as a feeling or way of being that "just is", while several considered it similar to positivity with Tony saying "my positivity and hopefulness definitely mould into the same thing". Because people did not have to engage with or act on this form of hope, they could appear passive. People were not always conscious of the presence of hope. Adrienne stated "I've never noticed it [hope]", "I'd never realised that [there was hope there]". Hope was considered essential for life and recovery. Miriam described it as "a matter of /rivin/ [living] or dying", saying that without hope "[she'd] be dead". While all participants experienced simply 'having' hope, there were subtle differences between these experiences. For some, it was constant and unaffected by the stroke while others felt hope was either out of reach immediately following the stroke, or was completely absent. Adrienne described the absence of hope as "a state of despair".

Hope was developed through multiple sources, with "other people" being the most common source of hope although they could also pose a risk to hope. Matthew reported gaining hope from "listening to what my kids tell me what they want to do" but also felt that "my kids and my wife have just have just, they just do something or say something and then it [hope] then it would all disappear". Other sources included people's spiritual beliefs and the stories and progress of other patients. The process of talking about hope helped 
Adrienne "realise there was hope there". Rehabilitation staff provided hope for some participants although this appeared to be influenced by the strength of the therapeutic alliance. When the therapist was perceived to be supportive and hopeful, it appeared to help the participants think positively and hopefully about the future. Seeing their own progress gave hope that they would continue to improve, with Tony saying: "Within four weeks I went from nothing to what I am now, so the hope is 'my God, I can go from zero'".

Hope appeared to increase when people transferred to less acute healthcare services as the transfer was considered an indicator of progress which further reinforced hope. Simply 'having' hope appeared to provide stability that allowed the participants to maintain hope that improvement was possible while they waited for change or a return to "normal", even when they were aware that this was uncertain. It was associated with having purpose, "having a chance" and "possibilities" and a reason for living. Miriam felt hope meant that "things [would] improve and get better", while Adrienne reported that the presence of hope calmed her and made her feel "just more normal ... (2 sec) more normal".

\section{ACTIVELY HOPING}

Actively hoping captured the sense that participants engaged with a future-oriented hope by identifying hopes for the future and working toward hopes. It appeared to involve two processes: identifying hopes for the future and working toward hopes. Actively hoping appeared more tenuous than simply 'having' hope, and was often experienced intermittently. 


\section{Identifying Hopes for the Future}

Hopes for the future appeared hierarchical, ranging from broad, personally meaningful hopes to specific, stroke-related hopes. Broad hopes arose from what was meaningful to the individual and their sense of self. They focused on roles in life, sense of identity, faith, and outlook on life. These hopes appeared relatively easy to identify and emerged from reflecting on past hopes and ways of being, on the present situation and their possible futures. Iosefa reported he hoped "to be Holy" while Miriam's hope was to "be as as ... (4sec) /bes/ [best] as you can be". Some participants suggested a layer of focused hopes which translated broad hopes into more specific hopes such as continuing theological study or passing values onto their children. All participants acknowledged a final layer of hopes related to the resolution of stroke-related impairments. These were relatively generic and were elicited by questions such as "Do you hope your speech will improve?" Only a few participants linked these hopes to their broader hopes.

Most participants also expected they would return to "normal" at some point in the future. The data suggested the difference between a hope and an expectation was the level of certainty related to the desired outcome - expectations were accompanied by a high degree of certainty that they would be achieved while hopes had a lower level of certainty attached to them. Expectations had a clear endpoint, were measurable and were commonly stroke-related, while hopes were broader, related to priorities in life and did not necessarily have a measurable outcome, for example, Matthew's hope of "being the best Dad I can be". 


\section{Working toward Hopes}

Participants suggested three steps would help hopes come about. Developing a plan or as Matthew stated, "just devising a way to do it", was commonly seen as difficult. This may be because many hopes were broad and didn't easily lend themselves to developing a plan. Miriam suggested putting in the effort required an individual to "just gotta /pa:/ [pull] [my]self up" and "work at it". The effort may be physical or cognitive, such as "doing the physio sessions" or "focusing on what you're working on" and appeared dependent on a certain level of motivation and/or volition. This was illustrated in Matthew's comment: "I do want to do it and um, but depending on how much I want to do it, I don't know". One participant was taking action to realise his hopes although it should be noted that his hopes and his action plan had been in place since before the stroke. While all participants reported they should take action, they felt it was difficult when hopes were broad or unclear, and while they were waiting for further improvement.

\section{INFLUENCES ON HOPE}

The findings suggested the experience of hope was fluid and changed in response to how people perceived their current situation and their future. These perceptions arose from uncertainty, their beliefs about hope and their sense of disruption. These factors could see individuals sometimes engage in actively hoping, while at other times they may retreat from the active form of hope, instead simply 'having' hope. 


\section{Uncertainty about the Future}

All participants experienced uncertainty about what their future may be. Adrienne expressed this with comments such as: "there's a lot of 'what will it [I] look like at the end [of recovery]', you know?”, "I don't know where I want to be in three months or a year's time", and "[the future] is out there". The person's response to the uncertainty, which was either acceptance or fear and vulnerability, appeared to influence their subsequent engagement in thinking about the future. As such, some were passive with regard to the future while others appeared to actively try to avoid thinking about the future. Adrienne reported feeling "terrified" about the future which meant that she tried not to think about it, instead taking things "a day at a time". At times, hopes and expectations for recovery dominated participants' views of the future while at other times, their uncertainty would dominate. When hopes and expectations dominated, they expressed anticipation and positivity about the future. When uncertainty dominated, the future became restricted and the focus returned to the present, focusing on "just getting through". At these times, instead of engaging in an active, future-oriented form of hope, their dominant experience of hope was simply 'having' hope, a passive, more present-focused form of hope.

\section{Double-sided Hope}

Hope was generally perceived as a "good thing" to have, however two participants, Matthew and Adrienne, reported a co-existing view that hope could be "very bad to have" as it could go unfulfilled. This was considered to pose a threat because it could result in disappointment or failure which could "linger". This view of hope appeared to be strongly influenced by previous experiences of hope. Matthew described the experience of 
unfulfilled hopes causing emotional distress. As a result, in "[his] brain, it's more more given up on that word [hope]". Similarly, Adrienne's previous experience of "everything [seeming] to go wrong" led her to be "always always afraid [that something might go wrong]". This double-sided view of hope was illustrated by Matthew's comment: "you can hope for lots of stuff but then half the time it's going to disappear"; and Adrienne's statement: “there's emotion part and a cognitive part you know. It's just the thing. It's horrible really". When participants viewed hope as a positive entity that would assist recovery, it appeared to support them in actively hoping. However, if like Matthew, they considered that hope had a "bad side", they were more likely to retreat from actively engaging with hope.

\section{Sense of Disruption}

Some participants experienced a significant amount of disruption to their identity and/or engagement in meaningful activities. While this was positive for some as it allowed them to pursue "different possibilities" and "do things differently", for others, it appeared that the combination of disruption, the daunting task of 'where to from here?' and a co-existing loss of identity influenced their experience of hope. Matthew was emphatic he didn't want to be the person he was before the stroke and thus, at one level, welcomed the chance to do things differently. However, when he tried to visualise what this might look like, the complexity of disruption became evident:

I sort of thought 'Oh, maybe. Maybe it's me' and then I then II thought about it you know, again the other night and I thought 'Oh nah, it's not me' and I just, I just I just can't agree whether it's me or not. 
Those participants who appeared to have greater disruption between their past and future and who were unsettled by the disruption, had more difficulty actively hoping as this required them to "move forward" and develop an image of the future. This resulted in their dominant experience of hope being simply 'having' hope.

\section{STRATEGIES FOR MANAGING THE TENSION AND FLUIDITY WITHIN HOPE}

As demonstrated in the findings presented above, hope was fluid, changing frequently and in a short period of time. For some, this resulted in a tension as they found themselves in a balancing act, trying to balance the influencing factors in order to maintain a sense of hope. As such, participants drew on a range of strategies in an attempt to manage the tensions in hope, which could further influence how they experience hope.

"Hunkering down" (as described by Miriam) occurred when uncertainty dominated thoughts about hope and the future. Participants retreated from actively hoping, instead focusing on the present, maintaining a sense of simply 'having' hope and focusing on "getting through" by taking it "a day at a time". Limiting engagement with hope by trying to not think about it or "[pushing] it away" occurred when participants viewed hope as double-sided or while they waited for their expectations to be fulfilled. Miriam utilised another strategy for managing uncertainty, keeping hopes broad, for example, "/gout/ [hope] ... (2 sec) you for better times to come [hope for better times to come]". Not specifying exactly what they hoped for offered some protection from disappointment from unfulfilled hopes. In addition, Miriam put limits on hopes, qualifying them with "step by step" and "one step at a time". This kept the focus on the near future. 
Common to all of these strategies is the notion that simply 'having' hope appeared to act as a stable footing that people needed in order to engage with hope in a more active way. It was a form of hope that people could come back to when they struggled to actively engage with hope. Simply 'having' hope was a state that could be relied on or defaulted to when a person was struggling with the complexities of hope.

\section{THE SIMPLICITY AND COMPLEXITY OF HOPE}

In summary, the experience of hope was, at one level, very simple - it was about simply 'having' hope and actively hoping. However, a number of factors appeared to make the process of hope more complex than it appeared at first glance. One reason it was so complex was that a person's experience of hope was dynamic and strongly influenced by their past experiences, their current reality and their perceived future. Uncertainty about the future could emerge when a person struggled to perceive what their future may be like; they often appeared 'caught' in their current reality. Double-sided hope emerged from previous experiences of hope and appeared to influence their current ability to actively hope. A sense of disruption could arise if there was a difference between a person's life prestroke and their perceived future. The hypothesised interaction between temporal and experiential factors influencing hope is demonstrated in Figure Two.

--- Insert Figure Two here ---

The complexity of hope could result in people engaging with hope, actively hoping and looking hopefully to the future, or it could result in them retreating from actively 
hoping, instead maintaining a sense of simply 'having' hope while they waited for things to change.

\section{DISCUSSION}

The two forms of hope, simply 'having' hope and actively hoping identified in this study are consistent with a number of studies of hope which have also described passive and active forms of hope (Arnaert, et al., 2006; Barnard, 2005). Studies of hope in stroke and other clinical populations support the finding that a sense of hope (resonating with simply 'having' hope) may be the most important form of hope (Barnard, 2005; Cross \& Schneider, 2010; Kim, Kim, Schwartz-Barcott, \& Zucker, 2006) and may help stroke survivors "[keep] the door open" to recovery (Barker \& Brauer, 2005, p. 1213). Simply 'having' hope bears similarities to what has been described as a general sense of hope, a sense of faith in the future which may protect against despair. It is not tied to particular timeframes or outcomes (Dufault \& Martocchio, 1985) and has been described as:

“... concerned with 'being' and is a rather nebulous, personal dimension that provides a sense of something beneficial to come, a positive glow, a global rather than focused component that provides motivation to carry on with life, a way of living in hope." (Greenstreet \& Fiddian, 2006, p. 63).

The current study of hope in people with aphasia suggests simply 'having' hope appeared to be the entry point into hope. It may serve as a 'safe' place where people can simply 'have' or 'be with' hope without needing to think too much about the future. People gained respite from the challenges of thinking about the future by reverting to simply 'having' hope. 
Actively hoping may be more difficult because of the uncertainty and limitations associated with recovery and chronic illness (Becker \& Kaufman, 1995; Carlsson, Moller, \& Blomstrand, 2009; Kim, et al., 2006; Rittman, et al., 2004). Uncertainty, common in the post-acute period after stroke (Becker \& Kaufman, 1995; Carlsson, et al., 2009; Kirkevold, 2002; Salter, Hellings, Foley, \& Teasell, 2008) can blur the image of a person's possible future (Hjelmblink \& Holmstrom, 2006), resulting in people being passive, waiting for their situation to change (Rittman, et al., 2004; Wallenbert \& Jonsson, 2005). This contributes to hope in the post-acute period being predominantly experienced as a passive sense of hope such as simply 'having' hope. The period of uncertainty may last for a year or two (Carlsson, Moller, \& Blomstrand, 2009; Eilertsen, et al., 2010) after which time, people engage in actively contemplating the future and developing meaningful hopes and activities (Brauer, Schmidt, \& Pearson, 2001; Eilertsen, et al., 2010; Kirkevold, 2002). It may be that people are more likely to engage in actively hoping later in recovery when they are more likely to be active in thinking about the future. Engaging in actively hoping during the post-acute period may also have been more difficult because of the sense of disruption which results in changes in how people view themselves and their future (Ellis-Hill, Payne, \& Ward, 2008; Hjelmblink \& Holmstrom, 2006). \}. It could be that actively hoping is more difficult for people with aphasia as it is strongly language-based and involves identification of specific hopes. In contrast, simply 'having' hope is primarily a broad inner sense and is not necessarily language based.

Some studies have suggested uncertainty could lead to hopelessness or despair (Kylmä, Vehvilainen-Julkunen, \& Lähdevirta, 2001; Sällfors, Fasth, \& Hallberg, 2002) but this was not evident in the current study. Participants appeared to draw on a number of 
strategies to manage uncertainty and protect themselves from perceived negative consequences of hope and it may be that the combination of strategies to maintain hope resulted in a sufficient sense of hope (simply 'having' hope) to sustain them in the face of uncertainty.

When participants engaged in actively hoping, they identified several levels of hopes ranging from broad hopes that related to priorities in life to specific hopes related to stroke recovery. These bore similarities to the hierarchy of life goals identified by Nair (Nair, 2003) but contrasted with many hopes identified in the stroke literature which focused on returning to normal or resolution of stroke deficits (Bright, et al., 2011) These were acknowledged by participants in this study but did not appear to constitute their primary hopes. There are several possible reasons why the main identified hopes within this study were broad and related to what was personally meaningful to the individuals. These include: that people's hopes are primarily about participation and engagement rather than recovery of specific functions; that people expected impairments to resolve and did not consider they needed to hope for these things to come about; or that broad hopes were easier for participants to discuss, possibly as a result of the aphasia. The questions asked influenced the responses with different questions identifying different aspects of the experience of hope. Similarly, the timing of interviews (at weekly intervals) gave participants the opportunity to reflect on the questions between the interviews and add any additional information to the probe questions. For example, asking "What does hope mean to you?" was a key question in exploring the sense of hope that a person had and their broad, personally meaningful hopes. Asking "How would you describe the word 'hope' to someone who didn't speak much English?" revealed information about the person's 
conceptualisation of hope. "What do you want to be doing in six months/one year?" was useful for exploring a person's uncertainty about the future, desired sense of self and priorities for recovery. More specific, impairment-related hopes were identified in response to more focused questioning such as "What do you hope for?" or closed questions such as "Do you hope to improve your speech?" The primary hopes identified in this study were consistent with some of the stroke recovery literature which suggests participants prioritise engagement in social worlds and personally meaningful activities (Brown, Worrall, Davidson, \& Howe, 2010; Haggstrom \& Lund, 2008; Wood, Connelly, \& Maly, 2010), sometimes over specific physical function (Burton, 2000).

Many hopes identified by participants related to their sense of identity and areas that were meaningful to the individual, that is, personally meaningful representations. These are considered important in being able to select lower-order goals (Emmons \& Kaiser, 1996; Nair, 2003; Ylvisaker, McPherson, Kayes, \& Pellet, 2008) a common component of rehabilitation. Goal-setting is recognised to be challenging for clinicians (Parry, 2004; Wressle, Oberg, \& Henrikson, 1999), particularly when the person has aphasia (Conneeley, 2004). It may be that exploring people's hope and hopes may help them identify desired identities and areas of importance, which may then facilitate engagement in goal-setting and rehabilitation (Ylvisaker, et al., 2008).

Participants in this study identified a number of sources of hope - family, friends, healthcare providers and other patients which is consistent with the hope literature (Arnaert, et al., 2006; Barker \& Brauer, 2005; Bays, 2001; Jones, et al., 2008; Popovich, et al., 2007; Pound, et al., 1994). This is supported by Green and Waks (2008); Christopher Green reported meeting another person with aphasia was important in helping him feel there was 
hope for his situation. This may be particularly important for people with aphasia who may not have heard of aphasia or met anyone with aphasia and hence have no benchmark for the progress that is possible.

While this study of hope in the post-acute period after stroke has contributed to developing knowledge of hope after stroke, particularly for people with aphasia, there are some limitations which must be acknowledged. The small number of participants meant that some participants with desired characteristics were not included. For example, we were unable to recruit any Māori participants, the indigenous people of New Zealand. In addition, those who declined to be involved or who were not approached by recruiting therapists may have offered different perspectives on the experience of hope. It is possible that those who consented to participate did so because they had experienced hope which meant they were more willing to participate. The degree of interpretation of raw data that was required due to the presence of aphasia may also have impacted on the findings. However, steps such as member-checking, consultation with experienced aphasia researchers and inclusion of raw data helped monitor the interpretation and provided transparency around the process. The robust approach to analysis using multiple analytic tools strengthened the study and may be a useful approach for other qualitative researchers working with people with aphasia.

This study makes a significant contribution to the aphasia literature by exploring the little-researched subject of hope, something that has been identified to be important to people with aphasia (Green \& Waks, 2008; Hersh, et al., 2012; Liechty \& Braun, 2006; Worrall, et al., 2009), at a time when many people with aphasia are accessing therapy services (Sarno, 2004). It highlights a number of implications for speech-language therapists 
and for health practitioners working with people with aphasia. It indicates clinicians should consider hope in people with aphasia after stroke as it is important to those people and it appears related to common components of the rehabilitation process such as goal-setting. Clinicians may play a role in supporting or reducing a person's level of hope whether they intend to or not. Understanding how a person experiences hope may help clinicians be mindful of their potential to influence it. This is particularly relevant as clinicians are more likely to consider hope as relating to specific hopes for recovery (Carter, McKenna, MacLeod, \& Green, 1998; Herrestad \& Biong, 2010; Soundy, et al., 2010) while data from this study suggest hopes for recovery are only a small component of the meaning and experience of hope in people with aphasia.

Hope may be addressed at different levels ranging from healthcare providers being aware, or mindful, of hope through to actively exploring and addressing hope (see Figure 3). Awareness of hope relates to considering the different ways an individual may experience hope, how this experience may influence their ability to participate in aspects of rehabilitation such as goal-setting, and awareness of factors such as uncertainty which may impact on both their experience of hope and ability to think about the future. Intentional exploration may occur if clinicians wish to explore hope in more detail by asking a range of questions, explicitly discussing it regularly and seeking to identify the individual's hopes for the future. Finally, active intervention may see clinicians intentionally try to foster hope in an individual, focusing on developing the therapeutic relationship to facilitate exploration of hope or implement interventions to help a person develop possible selves or a possible future. 
Future research is needed to explore hope at different time-points in recovery to understand how hope may change as people experience recovery. This study only discussed hope in people in the post-acute period. It is quite possible that the experience of hope may vary at different timepoints. The majority of participants in this study had anomic aphasia and one inclusion criteria was that participants could communicate with the researcher. Exploring hope in people with a broader variety of aphasia severities may provide additional information about the experience of hope. Exploring hope from the perspectives of other people such as family and healthcare providers may also be beneficial given their influence on how an individual experiences hope. The development of conceptually sound measures of hope specific to this population would allow for further research into the relationship between hope and rehabilitation outcomes. Exploring the applicability, acceptability and effectiveness of hope-fostering interventions in this population is also warranted.

\section{SUMMARY}

This study has demonstrated that people with aphasia following stroke consider hope is to be an important concept during the post-acute period of rehabilitation. It contributes to the body of knowledge about hope after stroke by increasing understanding of the ways in which hope is experienced; demonstrating that the experience of hope can be complex and dynamic due to the influence of a number of factors; and highlighting the possible implications of hope for rehabilitation. This study gives a voice to a client group 
who have often been excluded from research on hope after stroke and has explored hope in a way that has sought to maximise their ability to share their experience. 


\section{REFERENCES}

Alaszewski, A., Alaszewski, H., \& Potter, J. (2004). The bereavement model, stroke and rehabilitation: A critical analysis of the use of a psychological model in professional practice. Disability and Rehabilitation, 26(18), 1067-1078.

Arnaert, A., Filteau, N., \& Sourial, R. (2006). Stroke patients in the acute care phase: Role of hope in self-healing. Holistic Nursing Practice, 20(3), 137-146.

Barker, R., \& Brauer, S. (2005). Upper limb recovery after stroke: the stroke survivors' perspective. Disability and Rehabilitation, 27(20), 1213-1223.

Barnard, D. (2005). Chronic illness and the dynamics of hoping. In S. Toombs, D. Barnard \& R. Carson (Eds.), Chronic illness: From experience to policy (pp. 38-57). Bloomington, IN: Indiana University Press.

Barthel, G., M. Meinzer, et al. (2008). Intensive language therapy in chronic aphasia: Which aspects contribute most? Aphasiology. 22(4), 408-421

Bays, C. (2001). Older adults' descriptions of hope after a stroke. Rehabilitation Nursing, 26(1), 1827.

Becker, G., \& Kaufman, S. (1995). Managing an uncertain illness trajectory in old age: Patients' and physicians' view of stroke. Medical Anthropology Quarterly, 9(2), 165-187.

Bluvol, A. (2003). The Codman Award Paper: Quality of life in stroke survivors and their spouses: predictors and clinical implications for rehabilitation teams. AXON/ L'AXONE, 25(2), 10-19.

Brennan, A., Worrall, L., \& McKenna, K. (2005). The relationship between specific features of aphasia-friendly written material and comprehension of written material for people with aphasia: An exploratory study. Aphasiology, 19(8), 693-711. 
Bright, F., Kayes, N., McCann, C., \& McPherson, K. (2011). Understanding hope after stroke: A systematic review of the literature using concept analysis. Topics in Stroke Rehabilitation, 18(5), 490-508.

Brown, K., Worrall, L., Davidson, B., \& Howe, T. (2010). Snapshots of success: An insider perspective on living successfully with aphasia. Aphasiology, 24(10), 1267-1295.

Burton, C. (2000). Living with stroke: A phenomenological study. Journal of Advanced Nursing, 32(2), 301-309.

Carlsson, G., Moller, A., \& Blomstrand, C. (2009). Managing an everyday life of uncertainty - A qualitative study of coping in persons with mild stroke. Disability and Rehabilitation, 31(101), 773-782.

Carter, H., McKenna, C., MacLeod, R., \& Green, R. (1998). Health professionals responses to multiple sclerosis and motor neurone disease. Pallative Medicine, 12(5), 383-394.

Charmaz, K. (2006). Constructing grounded theory: A practical guide through qualitative analysis. Thousand Oaks, CA: Sage.

Cherney, L. \& Halper, A. (2008). Novel technology for treating individuals with aphasia and concomitant cognitive deficits. Topics in Stroke Rehabilitation. 15(6), 542-554

Conneeley, A. (2004). Interdisciplinary collaborative goal planning in a post-acute neurological setting: A qualitative study. British Journal of Occupational Therapy, 67(61), 248-255.

Cross, A., \& Schneider, M. (2010). A preliminary qualitative analysis of the impact of hope on stroke recovery in women. Topics in Stroke Rehabilitation, 17(6), 484-495.

Dorsett, P. (2010). The importance of hope in coping with severe acquired disability. Australian Social Work, 63(1), 83-102.

Dowswell, G., Dowswell, T., Lawler, J., Green, J., \& Young, J. (2002). Patients' and caregivers' expectations and experiences of a physiotherapy intervention 1 year following stroke: a qualitative study. Journal of Evaluation in Clinical Practice, 8(3), 361-365. 
Dufault, K., \& Martocchio, B. C. (1985). Hope: Its spheres and dimensions. Nursing Clinics of North America, 20(2), 379-391.

Eilertsen, G., Kirkevold, M., \& Bjørk, I. T. (2010). Recovering from a stroke: A longitudinal, qualitative study of older Norwegian women. Journal of Clinical Nursing, 19(13-14), 2004-2013.

Ellis-Hill, C., Payne, S., \& Ward, C. (2008). Using stroke to explore the Life Thread Model: An alternative approach to understanding rehabilitation following an acquired disability. Disability \& Rehabilitation, 30(2), 150-159.

Emmons, R., \& Kaiser, H. (1996). Goal orientation and emotional well-being: Linking goals and affect through the self. In L. Martin \& A. Tessler (Eds.), Striving and feeling: Interactions among goals, affect and self-regulation (pp. 79-98). Hillsdale, NJ: Lawrence Erlbaum and Associates.

Farran, C., \& Popovich, J. (1990). Hope: A relevant concept for geriatric psychiatry. Archives of Psychiatric Nursing, 4(2), 124-130.

Folden, S. (1994). Managing the effects of a stroke: the first months. Rehabilitation Nursing Research, 3(3), 70-85.

Green, C., \& Waks, L. (2008). A second chance: Recovering language with aphasia. International Journal of Speech-Language Pathology, 10(3), 127-131.

Greenstreet, W., \& Fiddian, M. (2006). Sustaining hope. In W. Greenstreet (Ed.), Integrating spirituality in hope and social care: Perspectives and practical approaches (pp. 62-75). Oxford, England: Radcliffe Publishing.

Gum, A., Snyder, C., \& Duncan, P. (2006). Hopeful thinking, participation and depressive symptoms three months after stroke. Psychology and Health, 21(3), 319-334.

Haggstrom, A., \& Lund, M. (2008). The complexity of participation in daily life: A qualitative study of the experiences of persons with acquired brain injury. Journal of Rehabilitation Medicine, 40(2), 89-95. 
Haggstrom, T., Axelsson, K., \& Norberg, A. (1994). The experience of living with stroke sequalae illuminated by means of stories and metaphors. Qualitative Health Research, 4(3), 321-337.

Herrestad, H., \& Biong, S. (2010). Relational hopes: A study of the lived experience of hope in some patients hospitalized for intentional self-harm. International Journal of Qualitative Studies on Health and Well-being, 5, 4651-4659.

Hersh, D., Worrall, L., Howe, T., Sherratt, S., \& Davidson, B. (2012). SMARTER goal setting in aphasia rehabilitation. Aphasiology, 26(2), 220-233.

Hjelmblink, F., \& Holmstrom, I. (2006). To cope with uncertainty: Stroke patients' use of temporal models in narratives. Scandinavian Journal of Caring Sciences, 20(4), 367-374.

Holloway, I., \& Wheeler, S. (2002). Qualitative research in nursing. Oxford, England: Blackwell Science.

Hopper, T., \& Edey, W. (2007. An exploration of hope and aphasia. Paper presented at the meeting of the Clinical Aphasiology Conference, Scottsdale, Arizona.

Hunt, M. (2009). Strengths and challenges in the use of Interpretive Description: Reflections arising from a study of the moral experience of health professionals in humanitarian work. Qualitative Health Research, 19(9), 1284-1292.

Jones, F., Mandy, A., \& Partridge, C. (2008). Reasons for recovery after stroke: A perspective based on personal experience. Disability and Rehabilitation, 30(7), 507-516.

Kagan, A. (1995). Revealing the competence of aphasic adults through conversation: A challenge to health professionals. Topics in Stroke Rehabilitation, 2, 15-28.

Kagan, A., \& Kimelman, M. (1995). Informed consent in aphasia research: Myth or reality? Clinical Aphasiology, 23, 65-75.

Kauhanen, M., Korpelainen, J., Hiltunen, P., Maatta, R., Mononen, H., Brusin, E., et al. (2000). Aphasia, depression, and non-verbal cognitive impairment in ischaemic stroke. Cerebrovascular Diseases, 10(6), 455-461.

Kertesz, A. (2006). Western Aphasia Battery-Revised: Harcourt Assessment Inc. 
Kim, D., Kim, H., Schwartz-Barcott, D., \& Zucker, D. (2006). The nature of hope in hospitalized chronically ill patients. International Journal of Nursing Studies, 43(5), 547-556.

Kirkevold, M. (2002). The unfolding illness trajectory of stroke. Disability and Rehabilitation, 24(17), 887-898.

Kirkland, C. (2008). Chronic aphasia: Life after treatment. Retrieved 17 March 2009, from http://cdswebserver.med.buffalo.edu/drupal/files/CA.\%20Kirkland-\%20Aphasia\%20Life\%20After\%20Treatment.pdf

KyImä, J., Vehvilainen-Julkunen, K., \& Lähdevirta, J. (2001). Hope, despair and hopelessness in living with HIV/AIDS: A grounded theory study. Journal of Advanced Nursing, 33(6), 764-775.

Liechty, J., \& Braun, M. (2006). Loss and hope: Strategies for coping with aphasia. Topics in Stroke Rehabilitation, 13(3), 84-86.

Lohne, V., \& Severinsson, E. (2004). Hope and despair: The awakening of hope following acute spinal cord injury - An interpretative study. International Journal of Nursing Studies, 41(8), 881-890.

Luck, A., \& Rose, M. (2007). Interviewing people with aphasia: Insights into method adjustments from a pilot study. Aphasiology, 21(2), 208-224.

Morse, J. M., \& Doberneck, B. (1995). Delineating the concept of hope. Image--The Journal of Nursing Scholarship, 27(4), 277-285.

Moss, A., \& Nicholas, M. (2006). Language rehabilitation in chronic aphasia and time postonset: A review of single-subject data. Stroke, 37(12), 3043-3051.

Nair, S. (2003). Life goals: The concepts and its relevance to rehabilitation. Clinical Rehabilitation, 17(2), 192-202.

Nekolaichuk, C. L., Jevne, R. F., \& Maguire, T. O. (1999). Structuring the meaning of hope in health and illness. Social Science and Medicine, 48(5), 591-605.

Nilsson, I., Jansson, L., \& Norberg, A. (1997). To meet with a stroke: Patients' experiences and aspects seen through a screen of crisis. Journal of Advanced Nursing, 25(5), 953-963. 
Parry, R. (2004). Communication during goal-setting in physiotherapy treatment sessions. Clinical Rehabilitation, 18(6), 668-682.

Pedersen, P., Jorgensen, H., Nakayama, H., Raaschou, H., \& Olson, T. (1995). Aphasia in acute stroke; Incidence, determinants and recovery. Annals of Neurology, 38(4), 659-666.

Pilkington, F. (1999). A qualitative study of life after stroke. Journal of Neuroscience Nursing, 31(6), 336-347.

Popovich, J., Fox, P., \& Bandagi, R. (2007). Coping with stroke: Psychological and social dimensions in U.S. patients. The International Journal of Psychiatric Nursing Research, 12(3), 1474-1487. Pound, P., Bury, M., Gompertz, P., \& Ebrahim, S. (1994). Views of survivors of stroke on benefits of physiotherapy. Quality in Health Care, 3(2), 69-74.

Rittman, M., Faircloth, C., Boylstein, C., Gubrium, J., Williams, C., Puymbroeck, M. V., et al. (2004). The experience of time in the transition from hospital to home following stroke. Journal of Rehabilitation Research and Development, 41(3A), 259-268.

Rose, T., Worrall, L., \& McKenna, K. (2003). The effectiveness of aphasia-friendly principles for printed health education materials for people with aphasia following stroke. Aphasiology, 17(10), 947-963.

Sällfors, C., Fasth, A., \& Hallberg, L. R. M. (2002). Oscillating between hope and despair - A qualitative study. Child: Care, Health and Development, 28(6), 495-505.

Salter, K., Hellings, C., Foley, N., \& Teasell, R. (2008). The experience of living with stroke: A qualitative meta-synthesis. Journal of Rehabilitation Medicine, 40(8), 595-602.

Sarno, M. (2004). Aphasia therapies: Historical perspectives and moral imperatives. In J. Duchan \& S. Byng (Eds.), Challenging aphasia therapies: Broadening the discourse and extending the boundaries (pp. 19-31). Howe, England: Psychology Press.

Simpson, C. (2004). When hope makes us vulnerable: A discussion of patient-healthcare provider interactions in the context of hope. Bioethics, 18(5), 428-447. 
Soundy, A., Smith, B., Butler, M., Lowe, C., Dawes, H., \& Winward, C. (2010). A qualitative study in neurological physiotherapy and hope: Beyond physical improvement. Physiotherapy Theory and Practice, 26(2), 79-88.

Tariah, H. A., Hersch, G., \& Ostwald, S. K. (2006). Factors associated with quality of life: Perspectives of stroke survivors. Physical and Occupational Therapy in Geriatrics, 25(2), 33-50.

Thorne, S. (2008). Interpretive description. Walnut Creek, CA: Left Coast Press.

Thorne, S., Kirkham, S., \& MacDonald-Emes, J. (1997). Interpretive description: A non-categorical qualitative alternative for developing nursing knowledge. Research in Nursing and Health, 20(2), 169-177.

Thorne, S., Kirkham, S., \& O'Flynn-Magee, K. (2004). The analytic challenge in interpretive description. International Journal of Qualitative Methods, 3(1), 1-11.

Wallenbert, I., \& Jonsson, H. (2005). Waiting to get better: A dilemma regarding habits in daily occupations after stroke. American Journal of Occupational Therapy, 59(2), 218-224.

White, J. H., Magin, P., Attia, J., Pollack, M. R., Sturm, J., \& Levi, C. R. (2008). Exploring poststroke mood changes in community-dwelling stroke survivors: A qualitative study. Archives of Physical Medicine and Rehabilitation, 89(9), 1701-1707.

Wood, J., Connelly, M., \& Maly, M. (2010). Getting back to real living: A qualitative study of the process of community reintegration. Clinical Rehabilitation, 24(11), 1045-1056.

Worrall, L., Davidson, B., Hersh, D., Howe, T., \& Sherratt, S. (2009). What do people with aphasia and their families want? Introducing the Goals in Aphasia Protocol. Paper presented at the meeting of the Speech Pathology Australia National Conference, Adelaide.

Wressle, E., Oberg, B., \& Henrikson, C. (1999). The rehabilitation process for the geriatric stroke patient - an exploratory study of goal setting and interventions. Disability and Rehabilitation, 21(2), 80-87. 
Ylvisaker, M., McPherson, K., Kayes, N., \& Pellet, E. (2008). Metaphoric identity mapping: Facilitating goal setting and engagement in rehabilitation after traumatic brain injury.

Neuropsychological Rehabilitation, 18(5/6), 713-741. 


\section{Appendix A: Transcription Guide}

.... ( $x \mathrm{~s}) \quad$ Signifies a pause in the participant's speech, length of pause (in seconds) is given in brackets

[ ] Indicates words added by the researcher to clarify the meaning of the quote

" " Indicates a direct quote from a participant or from the literature

'. Signifies a quotation within a participant's direct quote

// Indicates phonetic transcription using the International Phonetic Alphabet (IPA)

In addition,

- if the participant made phonemic paraphasic errors, the direct transcription of their speech is provided using the IPA and the target word is identified in square brackets,

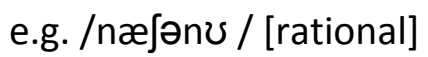

- if the participant made semantic paraphasic errors, these are provided in regular font and the target word is identified in square brackets, e.g. nurse [speech-language therapist] 
Table 1

\section{Participant Characteristics}

\begin{tabular}{|c|c|c|c|c|c|c|c|}
\hline & Gender & Age & Ethnicity & Type of stroke & $\begin{array}{l}\text { Time post- } \\
\text { stroke }\end{array}$ & Effects of stroke & $\begin{array}{l}\text { Aphasia quotient and } \\
\text { type }^{1}\end{array}$ \\
\hline Matthew & Male & 41 & Pākehā² & $\begin{array}{l}\text { SAH, left MCA } \\
\text { aneurysm }\end{array}$ & 4 months & $\begin{array}{l}\text { Aphasia } \\
\text { Mild right hemiparesis } \\
\text { Cognitive changes - memory, information } \\
\text { processing, attention }\end{array}$ & $\begin{array}{l}\mathrm{AQ}=83 \\
\text { Anomic aphasia }\end{array}$ \\
\hline losefa & Male & 43 & Samoan & Left MCA infarct & 3 months & $\begin{array}{l}\text { Aphasia } \\
\text { Cognitive changes - memory, information } \\
\text { processing, attention }\end{array}$ & $\begin{array}{l}\mathrm{AQ}=67.3 \\
\text { Conduction aphasia }\end{array}$ \\
\hline Miriam & Female & 62 & English & Left MCA infarct & 4 months & $\begin{array}{l}\text { Aphasia and apraxia of speech } \\
\text { Dense right hemiparesis } \\
\text { Neglect }\end{array}$ & $\begin{array}{l}\mathrm{AQ}=57.3 \\
\text { Broca's aphasia }\end{array}$ \\
\hline Adrienne & Female & 57 & Pākehā & $\begin{array}{l}\text { Left MCA infarct } \\
\text { due to left } \\
\text { sphenoid wing } \\
\text { meningioma }\end{array}$ & 5 months & $\begin{array}{l}\text { Aphasia and apraxia of speech } \\
\text { Moderate right hemiparesis } \\
\text { Limb apraxia } \\
\text { Cognitive changes - memory, planning, } \\
\text { sequencing } \\
\text { Visual perceptual deficits }\end{array}$ & $\begin{array}{l}\mathrm{AQ}=80.2 \\
\text { Anomic aphasia }\end{array}$ \\
\hline Tony & Male & 47 & Pākehā & Left MCA infarct & 2 months & Aphasia & $A Q=94.8$ \\
\hline
\end{tabular}

${ }^{1}$ Determined using the Western Aphasia Battery - Revised \{Kertesz, $\left.2006 \# 129\right\}$

${ }^{2}$ Pākehā is a term commonly used for non-indigenous New Zealanders 


\begin{tabular}{|ll|}
\hline $\begin{array}{l}\text { Multiple small } \\
\text { embolic infarcts }\end{array}$ & $\begin{array}{l}\text { Cognitive impairments - memory, attention, } \\
\text { executive functioning }\end{array}$ \\
\hline
\end{tabular}




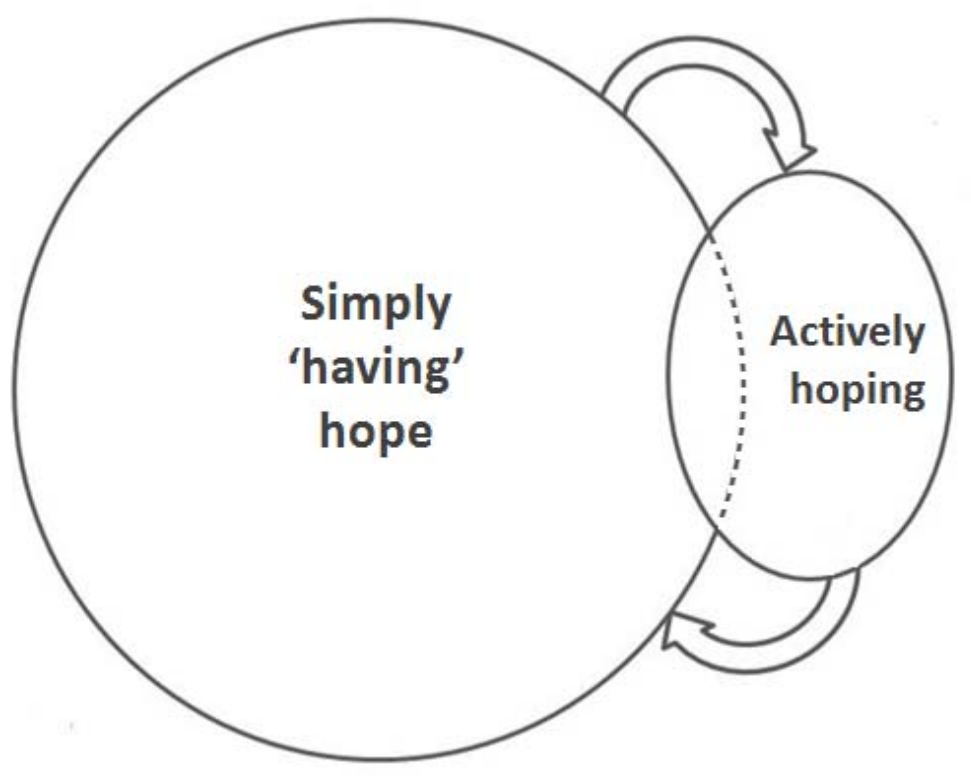

Figure 1: The simplicity and complexity of hope 


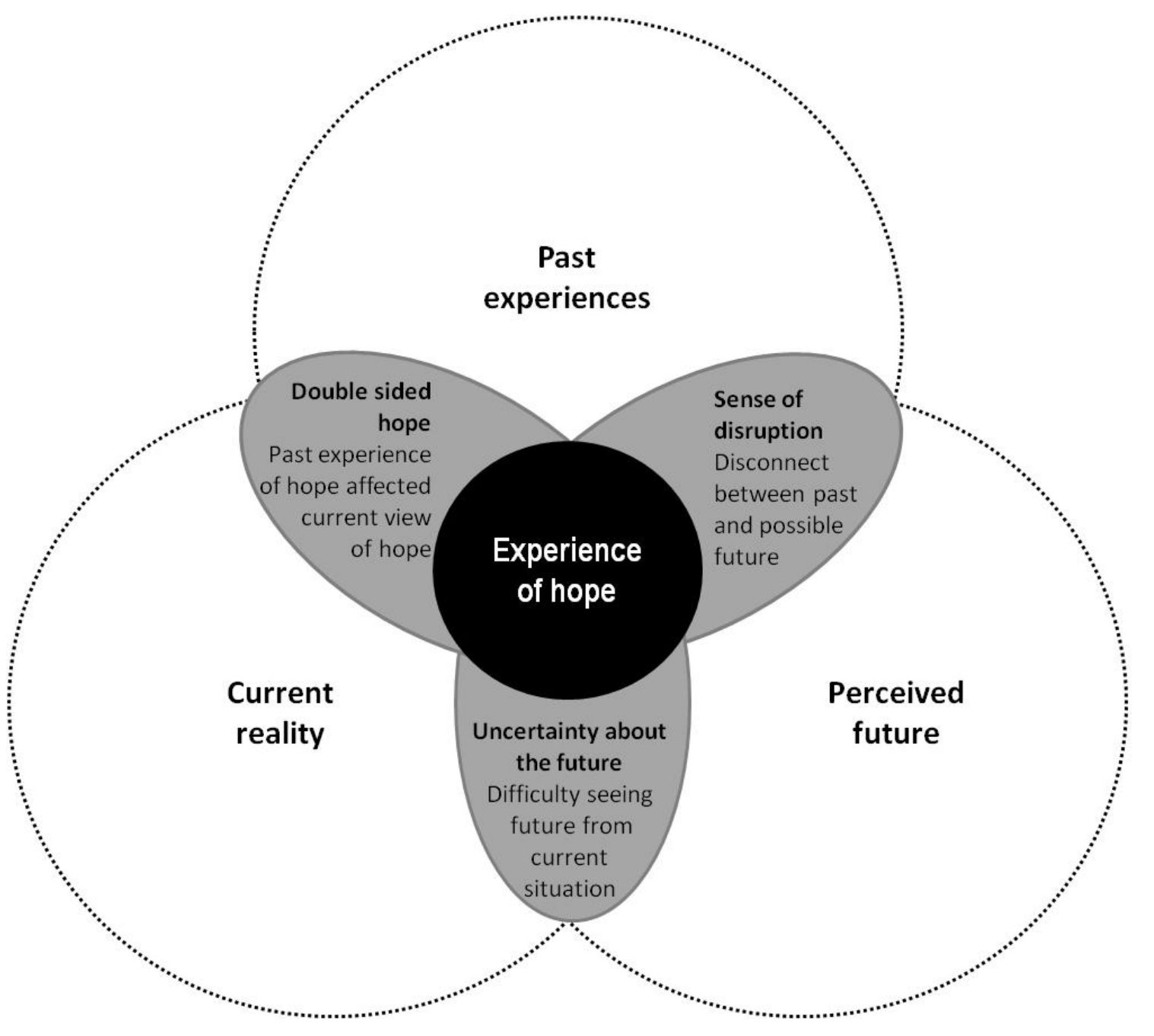

Figure 2: The simplicity and complexity of hope: The hypothesised relationship between temporal and experiential influences on hope 

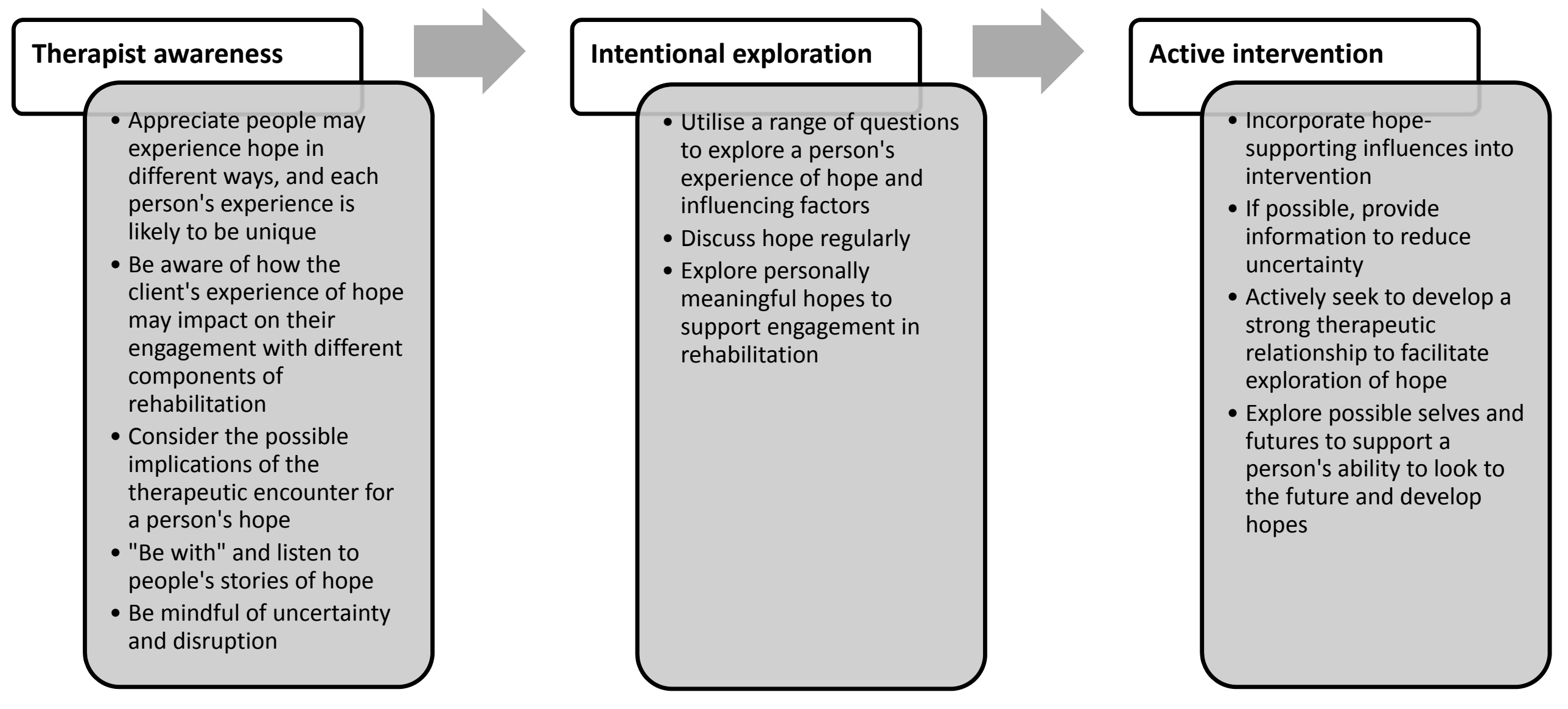

Figure 3. Clinical implications of hope 